\title{
The feasibility of computer-assisted survey interviewing in Africa: Experience from two rural districts in Kenya
}

\author{
Paul C. Hewett \\ Population Council \\ Annabel Erulkar \\ Population Council \\ Barbara Mensch \\ Population Council
}

Follow this and additional works at: https://knowledgecommons.popcouncil.org/departments_sbsr-pgy

Part of the Demography, Population, and Ecology Commons, Family, Life Course, and Society Commons, Health Information Technology Commons, and the International Public Health Commons How does access to this work benefit you? Let us know!

\section{Recommended Citation}

Hewett, Paul C., Annabel Erulkar, and Barbara Mensch. 2003. "The feasibility of computer-assisted survey interviewing in Africa: Experience from two rural districts in Kenya," Policy Research Division Working Paper no. 168. New York: Population Council. Version of record: https://doi.org/10.1177/ 0894439304263114 


\title{
The Feasibility of Computer-Assisted Survey Interviewing in Africa: Experience from Two Rural Districts in Kenya
}

\author{
Paul C. Hewett \\ Annabel S. Erulkar \\ Barbara S. Mensch
}

Paul C. Hewett is Research Associate and Barbara S. Mensch is Senior Research Associate, Population Council, New York. Annabel S. Erulkar is Staff Program Associate, Population Council, Kenya. 


\begin{abstract}
This paper explores the use of an audio computer-assisted self-interviewing (audio-CASI) methodology in a household survey of adolescents in two districts of Kenya. Computer software was developed as part of a research project comparing audio-CASI with traditional methods of interviewing about sensitive behaviors, including sexual initiation, risky sexual behavior, coerced sex, and drug and alcohol use. The paper describes the experience of carrying out a household-based study using computers and explores the technical challenges faced by the data collection teams. Few problems emerged with the computer hardware and software, despite the difficult interviewing conditions. The adolescent respondents easily adapted to the computerized interview and were able to complete the survey with minimal assistance from the interviewing staff. However, the computers were not a completely neutral part of the data collection process and added to problems encountered during the fieldwork in one of the districts. Unexpected findings regarding respondents' perceptions of privacy and confidentiality were also observed.
\end{abstract}

This material may not be reproduced without written permission from the authors. For a list of Policy Research Division Working Papers, including those available for downloading in PDF format, see www.popcouncil.org/publications/wp/prd/rdwplist.html. 
The use of computers in survey research in Europe and the United States is increasingly viewed as an efficient alternative to traditional interviewing techniques. Computer-assisted personal interviewing (CAPI) is increasingly replacing paper-and-pencil questionnaires in face-to-face surveys and is perceived as a practical way to reduce data entry costs, while increasing the accuracy of the data through programmed consistency checks and automated skip patterns. Computerized systems have also been used to collect data when the information requested is of a private or sensitive nature. Computer-assisted self-interviewing (CASI), by minimizing the respondent's interaction with the interviewer, reduces the respondent's predilection to modify or change answers. It has become the method of choice in the United States for surveys that collect information about sensitive behaviors. Table 1 describes the most common survey interviewing techniques.

As the costs of hardware decline and the availability of high-quality survey software increases, computer-assisted surveys will likely become more prominent; and with the integration of such programs with the internet, remote surveying technologies will increasingly be used. However, computer-assisted methods are less frequently used by researchers working in developing countries. In part this is a result of high startup costs

Table 1 Acronyms and descriptions of various survey interviewing techniques

\begin{tabular}{lll}
\hline Acronym & Name & Description \\
\hline CAPI & $\begin{array}{l}\text { Computer-assisted } \\
\text { personal interview }\end{array}$ & $\begin{array}{l}\text { An interviewer reads the questions from the computer screen } \\
\text { and records the respondent's answers directly into the } \\
\text { computer. }\end{array}$ \\
CASI & $\begin{array}{l}\text { Computer-assisted } \\
\text { self-interview }\end{array}$ & $\begin{array}{l}\text { The respondent reads questions from the computer screen } \\
\text { and records his or her answers using a keyboard or keypad. }\end{array}$ \\
Audio-CASI & $\begin{array}{l}\text { Audio computer- } \\
\text { assisted self- }\end{array}$ & $\begin{array}{l}\text { The respondent listens to the questions from computer using } \\
\text { audio headphones and records his or her answers using } \\
\text { a keyboard or keypad. The respondent may or may not } \\
\text { simultaneously read the questions from the computer screen. }\end{array}$ \\
PAP-IA & $\begin{array}{l}\text { Paper and pencil: } \\
\text { Interviewer- } \\
\text { administered }\end{array}$ & $\begin{array}{l}\text { An interviewer asks all questions and records the respondent's } \\
\text { answers on a paper questionnaire. The information is then } \\
\text { entered into a computer by data entry staff. }\end{array}$ \\
PAP-SA & $\begin{array}{l}\text { Paper and pencil: } \\
\text { Self-administered }\end{array}$ & $\begin{array}{l}\text { The respondent reads and answers all questions directly on a } \\
\text { paper questionnaire. The information is then entered into a } \\
\text { computer by data entry staff. }\end{array}$ \\
& &
\end{tabular}


of equipment for larger surveys and the technical difficulties of field research in less developed societies. It is also a consequence of the lack of familiarity with computers among the local population, as well as their significantly lower levels of educational attainment. These problems affect not only the ability of respondents to use the computer, but potentially affect their perception of the confidentiality, privacy, and security of personal information they provide.

This paper reviews the use of computerized interviewing in a household-level survey in Kenya. As part of ongoing research on adolescent sexual behavior among adolescents, audio-CASI technology was employed to obtain information about sensitive issues, including sexual initiation, risky sexual behavior, coerced sex, and drug and alcohol use. The research was based on household-level surveys of more than 6,000 adolescents in rural Kenya. To compare the fieldwork experiences of various interview methods, as well as the substantive differences in reporting of sensitive behaviors, a quasi-experimental design was developed using three interviewing methodologies as described below.

With detailed analyses of the substantive findings of the study available elsewhere (Mensch, Hewett, and Erulkar 2001, 2003), this paper explores the technical aspects of the research and evaluates the feasibility and experience of implementing a computer-assisted, household-level survey in a developing-country setting. The paper first explores the literature on the use of computer-assisted interviewing in survey research. It then provides an overview of the quasi-experimental framework and related methodology and reviews the technical aspects of the audio-CASI design. It also considers the results of the fieldwork and the reaction of community members and respondents to the project and survey. The paper concludes with a discussion of the project findings and recommendations for future studies.

\section{BACKGROUND AND LITERATURE REVIEW}

Computer-assisted interviewing technologies have been in existence for more than three decades. ${ }^{1}$ With the introduction of personal computers, computerized interviewing has increasingly become a tool of survey researchers, primarily because it is believed to improve the quality of survey data while decreasing the cost of collection. Interviewing programs have been developed that offer a variety of advantages over pa- 
per-and-pencil interviewer-administered surveys, including entry validation, automated skip and branching for complex questionnaires, and internal consistency checks. Computerized interviews also eliminate the need for secondary data entry and cleaning, further enhancing data quality by removing keystroke errors. These advantages have propelled the use of computers for survey interviewing (Couper and Nicholls 1998).

The movement toward computerized interviewing was more firmly established when it came to be considered a more reliable method for collecting data in surveys that contained sensitive or socially stigmatizing questions (Turner et al. 1998b). Because of a longstanding concern that respondents underreport sensitive behaviors in face-to-face surveys, alternative methods for obtaining more accurate reporting from respondents have been pursued (Warner 1965; Bradburn et al. 1978, 1979). Although the use of computer-assisted personal interviewing did not resolve this problem, since the interviewer still asked the questions and entered the respondent's answers into the computer, computerized self-administered surveys allow respondents to interact directly with the computer, eliminating the interviewer. Such computer-assisted self-interviews provide a more confidential and private context in which respondents are believed to be more comfortable responding to sensitive questions. Although paper-and-pencil self-administered surveys are similar with regard to their level of privacy, respondents often have problems completing even simple versions of these questionnaires, increasing the prevalence of missing and nonresponse data. With the use of computers to manage the interview, CASI surveys are able to be as structurally complex as paper-and-pencil interviewer-administered surveys, while still providing the anonymity of self-administration. Variants of the computerized interview have been developed to overcome other problems, such as audio-CASI surveys for populations with low levels of literacy or touchscreen technologies to eliminate respondents' use of the keyboard.

A large number of empirical studies have been conducted in developed countries to test whether computerized interviews provide greater reporting of sensitive behaviors. Such studies typically use quasi-experimental designs to randomly assign respondents to different interview modes. A wide range of sensitive questions have been incorporated in these analyses, including questions about sexual behavior (Turner et al. 1998a; Tourangeau and Smith 1996), drug and alcohol use (Acquilino 1994; Acquilino and Lo 
Scuito 1990; Beebe et al. 1998), racial attitudes (Kyrsan 1998), and the reporting of induced abortion (Fu et al. 1998). Although some studies have found little difference between computerized and noncomputerized self-administration (Jobe et al. 1997; Johnson et al. 2001; Millstein and Irwin 1983), consistently higher reporting is found when comparing CASI and audio-CASI to interviewer-based surveys (Turner et al. 1998; Tourangeau and Smith 1996; Fu et. al. 1998; O'Reilly et al. 1994).

Public health researchers and epidemiologists have also evaluated the impact of interview mode on response patterns, with particular interest in sexual behavior and drug use related to risk for sexually transmitted diseases and HIV (Macalino et al. 2002; Fenton et al. 2001; Metzger et al. 2000). Research from a public health perspective has focused on reporting and participation biases both in high-risk groups (Williams et al. 2000; Des Jarlais et al. 1999; Boekeloo et al. 1994) and in the general population (Johnson et al. 2001; Copas et al. 1997). These studies have generally found that CASI and audioCASI provided increased reporting of intravenous drug use, multiple sexual partners, and unprotected sex. The dominant paradigm that has emerged from the social science and public health perspectives is that computerized administration of questionnaires related to sensitive behaviors increases the reporting of such behaviors and provides a more efficient and effective means to implement self-administered surveys.

As mentioned earlier, computerized interviews are the method of choice for surveys in the United States that collect data on sensitive questions. Although a large number of studies in developing countries have also focused on sensitive behaviors-particularly sexual behavior - and although the cultural and traditional values of many countries would render the candid reporting of such behaviors unlikely (Mensch, Hewett, and Erulkar 2001,2003), survey researchers in developing countries have only recently begun to incorporate the use of CASI and audio-CASI technologies. Research exploring the use of computerized interviewing in developing countries includes small-scale feasibility studies in Zimbabwe (van de Wijgert et al. 2000), Kenya (Voeten et al. 2000), and Thailand (Rumakom et al. 1999), as well as a more extensive study of alternative interviewing methods in Mexico (Lara et al. 2001).

In particular, van de Wijgert et al. evaluated whether women with little or no familiarity with computer technology were able to adapt to a self-administered audio- 
CASI interview. Because their interest was in the feasibility of computerized administration, rather than on whether audio-CASI provided more reliable data, the investigators used no sensitive questions in the survey. The study was based on a convenience sample of approximately 220 women aged $18-50$ years distributed across three educational groups: completed primary education or less, some or completed high school, and university graduates. The results indicate that, in general, respondents were able to use the computer effectively; however, the ability to master the tasks of completing the survey varied by education, with significantly greater difficultly in reading the questions on the screen and using the keyboard among those with little or no education. In all educational groups the overwhelming majority of women preferred being interviewed with audio-CASI, suggesting that it provided greater privacy and confidentiality than the interviewer-administered survey. These results indicate a positive reception of audio-CASI among women who were not previously familiar with computerized interviewing. The authors suggest (van de Wijgert et al. 2000: 889) that with more user-friendly computerized surveys, audio-CASI could be used as an alternative to paper-and-pencil self-administered surveys for collecting data in a developing country.

\section{RESEARCH AND STUDY DESIGN}

The project reported on here was carried out in Nyeri district within Central Province and in Kisumu district within Nyanza Province in Kenya. Nyeri was selected because previous findings indicated that adolescent girls underreported sexual activity (Mensch et al. 1998). Kisumu was selected because of the high prevalence of HIV, hence the importance of accurately capturing levels of adolescent sexual activity and contraceptive use.

Nyeri, approximately 100 kilometers north of Nairobi, is a rural district with a small central town with a population of approximately 600,000 in 1999. Because of its fertile soil and tropical climate, the district has historically been economically better off, producing tea and coffee as cash crops for domestic and foreign markets. However, given the deterioration of the local economy and the retrenchment of Kenya's economy in general, Nyeri has experienced significant economic decline in recent years. The region contains largely ethnic Kikuyus and at the time of data collection was the geographic center of political opposition in Kenya. 
Kisumu district is approximately 200 kilometers northwest of Nairobi and borders Uganda. Its 1999 population was a little more than a half-million people, 43 percent of whom live in periurban areas within and around Kisumu township, with the rest residing in rural areas. Kisumu is inhabited primarily by the Luo ethnic group and historically has been economically less well off than Nyeri, with the majority of rural residents participating in subsistence farming, animal husbandry, and fishing. As a connection point in the rail line running from Kampala to Mombasa, Kisumu township has a small industrial and manufacturing base.

\section{Research design and sample}

The study was based on a quasi-experimental design in which unmarried adolescent boys and girls aged 15-21 years were randomly assigned to one of three interview methods: traditional face-to-face interviews, paper-and-pencil self-administered interviews, and audio-CASI interviews. ${ }^{2}$ Adolescents were drawn from selected locations and sublocations within each district using population estimates from the 1989 (Nyeri) and 1999 (Kisumu) national census. ${ }^{3}$ Given the lower population density in Nyeri, all enumeration areas in a particular sublocation were selected and saturated sampled. In Kisumu, a fixed sampling fraction of enumeration areas was determined and a single enumeration area was randomly sampled. To complete the sampling fraction, contiguous enumeration areas were selected to minimize the logistical costs of fieldwork. Approximately 4,200 adolescents in Nyeri and 2,100 in Kisumu were targeted for interviews based on conventional sample size estimates for detecting statistically significant differences in proportions (Cohen 1992; Murphy and Myors 1998; Mensch, Hewett, and Erulkar 2001). The smaller sample in the Kisumu study was the result of a tighter budget for the fieldwork, as well as the large differentials in the reporting of sexual behavior according to interview mode found in Nyeri. With differences approaching 20 percent across the interviewer and audio-CASI modes in Nyeri, a smaller sample size was required in Kisumu to achieve similar levels of statistical significance. Fieldwork for Nyeri occurred between May and October 2000; for Kisumu fieldwork took place between April and July 2002. 
To achieve the target number of respondents in each of the two districts, identification of all household members within a selected enumeration area was completed in the days prior to interviewing adolescents. If there was an adolescent in the household, he or she was randomly assigned to one of the three interviewing modes. ${ }^{4}$ Appointments were made for the interview with the adolescent, and the interviewer returned the following day or shortly thereafter. Eighteen interviewers, divided into three teams of six interviewers, were recruited for the fieldwork in each district. While all interviewers were trained to complete a household survey, which included a listing of all household members, each interviewer specialized in one of the three modes of interview for the adolescent survey. Interviewers were paired by interview method, interviewing samesex respondents only. ${ }^{5}$ Each team of six interviewers was assigned one supervisor to oversee field logistics and data quality. To facilitate community acceptance, interviewers were recruited from the district, ensuring that they were from the same ethnic group as the respondents and spoke the local language. The interviewers were also relatively young, ranging in age from 20 to the mid-30s, and many had prior survey interviewing experience. During the fieldwork, interviewers were asked to keep journals and to record their observations about the data collection.

The questionnaires used in the study were relatively short: 65 questions were asked in Nyeri and 69 questions in Kisumu; two-thirds of the questions were considered sensitive, asking respondents about their sexual behavior, alcohol and drug use, contraceptive practice, pregnancies, induced abortions, and births. Most of the questions had been used in earlier studies of adolescent sexual behavior conducted in Kenya and elsewhere. Upon completion of the main interview, an exit interview was conducted that asked the respondents questions regarding their feelings about the survey and the interview. The exit interview also included questions about the interview context, for example whether anyone else was present or whether the respondent had trouble completing the questionnaire.

\section{Audio-CASI technology and design}

The initial costs of the audio-CASI component consisted of the purchase of six low-end Toshiba ${ }^{\mathrm{TM}}$ notebook computers, six external mini-keypads, and 12 spare note- 
book batteries (three for each unit). ${ }^{6}$ The audio-CASI software was programmed using Microsoft Visual Basic ${ }^{\mathrm{TM}}$ version 6.0 and Access $2000^{\mathrm{TM}}$. The startup software and hardware cost was about $\$ 2,000$ per interviewer at the initiation of the project in February $2000 .^{7}$ At the time of the fieldwork, alternative technologies, such as handheld computers, did not offer audio playback and had limited hard drive capacity. ${ }^{8}$

Although a variety of commercial CASI products are available, none adequately fit the particular design and objectives of the research. Hence, a customized audioCASI program was developed using Microsoft Visual Basic programming and Access database software. The audio-CASI software program was database driven, meaning the database defined the structure and content of the survey interview (question order, response categories, skip patterns, termination points, etc.). Visual Basic served as a programming shell to integrate the hardware and software components. The audio files containing the instructions and questions that were heard by the respondent were generated using digital recording software and were linked to the audio-CASI program from the database in the form of file name and location specifications. ${ }^{9}$ The benefit of such an approach is that the organization of the questionnaire and the management of the audio files were achieved completely within the database. This made changing the questionnaire design relatively straightforward and allowed the CASI program to be adapted to new survey instruments without making significant changes to the programming code.

Whereas previous CASI studies required respondents to be literate and trained in the use of a computer and keyboard, this study simplified the process. In both Nyeri and Kisumu, the computer remained closed and in its carrying case during the interview. The respondent used a set of audio headphones to listen to the questions and the response options. The adolescent answered the questions by using an external mini-keypad that included numbers and two color-coded keys, a red key for replaying the question and a blue key to enter a response. With this purely audio design, as opposed to the design where audio is combined with a visual component, the number of response options is limited because of potential difficulties remembering the categories that have been heard. In our survey, questions varied in the number of response categories: 70 percent of the questions were of a dichotomous (yes, no) format. The remaining had multiple options, 
up to a maximum of six, which we found posed no significant problem for the respondent. Of course, open-ended responses were not possible.

In each district, the respondents could select one of three languages for the interview, English, Kiswahili, or the local language. In Nyeri, after each answer was entered, the computer repeated the response entered and the adolescent was given an opportunity to change it. This repetition of answers was used to minimize data entry errors, by allowing respondents to confirm or alter their answers. This process was changed in Kisumu, where the playback of the adolescent's responses was removed from the program. ${ }^{10}$

\section{RESULTS AND FINDINGS}

As noted earlier, computerized interviewing has rarely been used in the developing world. Only recently have new technologies reduced the costs and technical difficulties of fielding studies where paved roads are lacking and access to electricity is unreliable. In addition, safety issues are of concern, particularly in field-based studies in urban and slum areas. And given the population's limited exposure to computers, there is a concern that respondents would be unable to master a computerized interview and would view the computer with trepidation. Their perceptions of privacy and confidentiality of the computerized interview are also difficult to determine. Thus, in addition to evaluating the different levels of reporting of sensitive behavior by interview mode, the project set out to test the feasibility of conducting computerized interviewing in householdbased surveys in a rural, sub-Saharan African country and to evaluate the reaction to the computer among adolescents, parents, and other adults in participating communities.

To anticipate the findings, our experience indicates that technological challenges do not pose a major hurdle in implementing a field study using mobile computer equipment. Moreover, adolescents' reactions to the computer were generally positive, and the difficulties of training respondents to properly use the equipment were minimal. On the other hand, in terms of achieving the substantive goals of the project—obtaining more accurate reporting of sensitive behaviors-it appears that reactions to the survey generally, and to the computer specifically, were dependent on the local context in which the survey was carried out (Mensch et al. 2001, 2003). These issues will be discussed further below. 


\section{Technological challenges}

The computer hardware held up surprisingly well during the six months of fieldwork in Nyeri and four months of fieldwork in Kisumu. The household-based survey involved daily interviewing in remote rural areas and difficult physical conditions, including dirt roads, narrow paths, and rocky terrain. Interviewing in Kisumu also took place during the rainy season when daily thunderstorms were common. Surprisingly, the technological components that presented the most difficulty were the external mini-keypads and the computer batteries. Additional keypads and batteries had to be provided throughout the study because of various problems and malfunctions, slightly increasing the costs of the audio-CASI element. However, no significant problems were found with the computer hardware or software, and no computers were stolen during the fieldwork.

As part of the exit interview, audio-CASI interviewers were asked to complete a question on whether they experienced any technology failures during the interviews. Figure 1 shows the summary distribution of such problems. Interviewers reported at least one technical problem in 20 percent of the audio-CASI interviews, with 5 percent of interviews having more than one problem (not shown). The predominant source of technical problems was the external keypad, with 15 percent of the interviews affected

Figure 1 Reporting of technical problems by interviewers during the audio-CASI survey

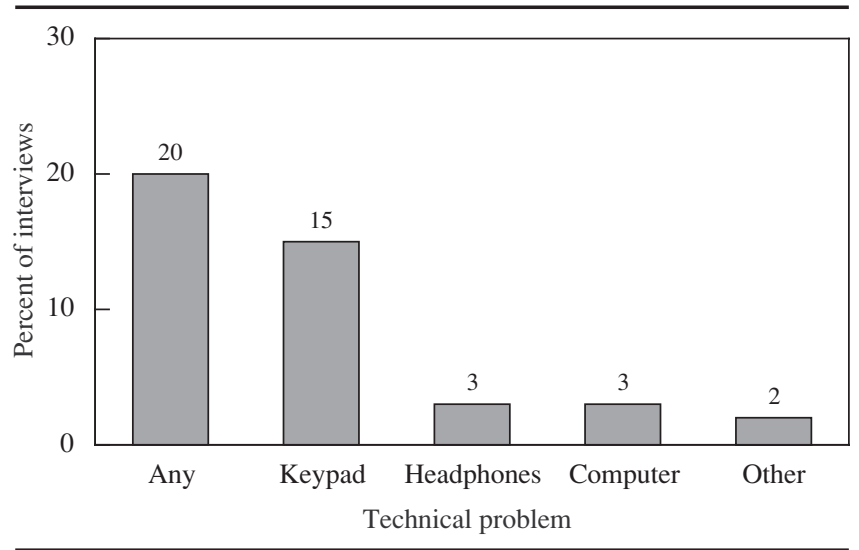

NOTE: The figure includes both Nyeri and Kisumu districts, since the distribution across the two districts is virtually identical. 
by such problems. These were primarily due to the sensitivity of the keypad, for example the failure to record a response or recording multiple responses for a single keystroke. Figure 1 also reveals the marginally small number of cases in which the computer malfunctioned, with a computer malfunction reported in only 3 percent of more than 6,000 surveys.

For the most part the hardware problems did not completely disrupt interviews. Of the total number of audio-CASI interviews, approximately 9 percent were incomplete owing to technology failures in Nyeri and 3 percent were incomplete in Kisumu. In a small number of cases $(n=29)$, interviews could not be repeated either because adolescents were unwilling to be re-interviewed or because fieldworkers were unable to reschedule an interview within an accommodating time frame. ${ }^{11}$

\section{Respondent reaction and evaluation}

At the start of the project, it was not known whether the adolescents would adapt to and successfully complete the computerized interview. Although most Kenyan children in the 15-21 age group have attended primary school, with 90 percent completing at least four years (Lloyd, Kaufman, and Hewett 2000), very few have ever used or even seen a computer. Although the design of the audio-CASI element minimized the interaction between the respondent and the computer by using an external mini-keypad and headphones, there was still a concern that even these elements could prove difficult for the adolescents to use.

These fears were shown to be unfounded. In a round of pretesting outside of Nairobi, adolescents quickly adapted to using the equipment. They responded enthusiastically to the computer and stated that they felt more comfortable using it to answer questions. ${ }^{12}$ From the exit interviews collected during the main fieldwork, interviewers noted that 75 percent of adolescents in Nyeri and 84 percent in Kisumu understood how to use the keypad and headphones "very well." Most others understood the headphones and keypads "moderately well," with only 2 percent of interviewers indicating that the respondents had difficulty using the equipment to complete the survey. These findings provide evidence that the technological problems cited in Figure 1 were not directly related to the adolescents' ability to use the keypad. 
Additionally, interviewers recorded the number of times respondents asked for assistance during the interview. These results by interview mode are shown in Table 2 . Because van de Wijgert et al. (2000) found that the ability to use audio-CASI was related to the education of the respondent, the data are also broken down by educational attainment. If respondents had greater difficulty with the computerized interview, there should be a higher percentage of cases in which the audio-CASI respondents stopped and asked the interviewer for assistance during the interview. ${ }^{13}$ In both Nyeri and Kisumu, however, audio-CASI respondents were less likely to ask for assistance than respondents in either the interviewer-administered or self-administered modes, although the differences are greater in Kisumu. In Nyeri, respondents found the self-administered questionnaire the most difficult to complete, paralleling previous research that highlights the difficulties respondents have completing self-administered questionnaires (Tourangeau and Smith 1998). In Kisumu the interviewer-administered mode, relative to the self-administered and audio-CASI methods, seems to elicit a higher percentage of cases where clarification was required, although it is difficult to specify the reasons for this.

These effects are also moderated by education levels. For instance, less-educated respondents in Nyeri had more trouble completing the self-administered survey, with 72 percent of respondents with a primary school education or less asking for assistance,

Table 2 Percent of respondents asking for assistance or clarification one or more times during the interview, by interview mode and educational attainment

\begin{tabular}{|c|c|c|c|c|c|c|}
\hline & \multicolumn{3}{|c|}{ Primary or less } & \multicolumn{3}{|c|}{ Secondary } \\
\hline & $\begin{array}{c}\text { Paper-and- } \\
\text { pencil inter- } \\
\text { viewer-admini- } \\
\text { stered }\end{array}$ & $\begin{array}{l}\text { Paper-and- } \\
\text { pencil self- } \\
\text { admini- } \\
\text { stered }\end{array}$ & $\begin{array}{l}\text { Audio- } \\
\text { CASI self- } \\
\text { admini- } \\
\text { stered }\end{array}$ & $\begin{array}{l}\text { Paper-and- } \\
\text { pencil inter- } \\
\text { viewer-admini- } \\
\text { stered }\end{array}$ & $\begin{array}{l}\text { Paper-and- } \\
\text { pencil self- } \\
\text { admini- } \\
\text { stered }\end{array}$ & $\begin{array}{l}\text { Audio- } \\
\text { CASI self- } \\
\text { admini- } \\
\text { stered }\end{array}$ \\
\hline \multicolumn{7}{|l|}{ Nyeri } \\
\hline 1-3 times & 49 & 47 & 39 & 43 & 43 & 37 \\
\hline 4+ times & 3 & 25 & 9 & 4 & 7 & 8 \\
\hline Sample size & 1,040 & 999 & 818 & 497 & 492 & 464 \\
\hline \multicolumn{7}{|l|}{ Kisumu } \\
\hline 1-3 times & 47 & 33 & 32 & 46 & 30 & 27 \\
\hline 4+ times & 1 & 8 & 4 & 2 & 6 & 2 \\
\hline Sample size & 349 & 325 & 360 & 361 & 359 & 417 \\
\hline
\end{tabular}


versus 50 percent of respondents with a secondary school education. In Kisumu, a similar pattern is observed by education levels, but the effect is much less pronounced. Audio-CASI also reveals differentials by education in both Nyeri and Kisumu, but not to the degree observed in the self-administered surveys or by van de Wijgert. Perhaps this is due to the marginal difference in primary versus secondary education in obtaining the skills required to use the audio-CASI technology.

To further capture how well respondents adapted to the computer technology, counters programmed into the audio-CASI software used in Kisumu recorded the number of times questions were repeated and the number of invalid responses typed into the keypad during the survey. ${ }^{14} \mathrm{~A}$ tally of these counters can be observed in Table 3. It is clear from the table that respondents using the audio-CASI system often played the questions multiple times. Surprisingly, respondents with secondary schooling were slightly more likely to repeat a question during the interview (57 percent versus 50 percent). Further, those who repeated questions in audio-CASI were twice as likely to ask for assistance during the course of the interview (results not shown).

An additional set of individual counters for ten specific questions was included in the audio-CASI survey in Kisumu. The ten questions varied in sensitivity, complexity, and placement in the survey. ${ }^{15}$ It was thought that respondents might be more likely to replay longer questions or questions with a higher number of response options in an effort to improve their memory and understanding. Additionally, there was speculation as to whether respondents would become accustomed to the computerized interview in the course of the survey, thus reducing the need to replay questions over time. Neither the length of the question nor the number of response categories seemed to affect how often the question was replayed (results not shown). Also, questions that came earlier in

Table 3 Percent of respondents who replayed a question or entered an invalid response one or more times in audio-CASI, by education, in Kisumu district

\begin{tabular}{lccccc}
\hline & \multicolumn{2}{c}{ Repeated questions } & & \multicolumn{2}{c}{ Invalid entries } \\
\cline { 2 - 3 } \cline { 5 - 6 } & Primary or less & Secondary & & Primary or less & Secondary \\
\hline $1-3$ times & 24 & 21 & & 37 & 43 \\
$4+$ times & 26 & 36 & & 37 & 19 \\
Sample size & 548 & 206 & & 548 & 206 \\
\hline
\end{tabular}


the survey were no more likely to be replayed than those that appeared later. Timers also captured how long it took for the respondent to answer each of the ten questions. Although we thought respondents might take longer to answer sensitive questions, there was little evidence that this was the case. The average times were similar for all questions, ranging from 1.17 seconds to 1.51 seconds.

The righthand panel of Table 3 shows the percent of invalid entries during the survey by education. Respondents keyed in a surprisingly high number of invalid responses, with a greater proportion among those with primary school education or lower. This effect is particularly pronounced for female respondents (results not shown), with 82 percent of less-educated females entering at least one invalid entry during the audioCASI interview, compared with 66 percent for adolescent girls with a secondary education. Although these invalid entries were not accepted by the audio-CASI program, and respondents were asked to reenter their responses, these figures suggest that respondents were having more problems using the keypad than the interviewers were able to detect. ${ }^{16}$ Of course, some of the invalid responses were due to the technological problems with the keypad that occurred during the interview, including instances where single keystrokes by the respondent led to multiple values being recorded by the audio-CASI program, although it is also clear from Figure 1 that these problems alone cannot account for the large number of invalid entries.

An area of concern in evaluations of self-administered interview methods is the number of questions with missing answers and nonresponses, including out-of-range, nonsensical, and refused responses. Table 4 provides an overview of the proportion of

Table 4 Percent of cases with missing or nonresponse data by interview mode

\begin{tabular}{lccc}
\hline & $\begin{array}{c}\text { Paper-and-pencil } \\
\text { interviewer-administered }\end{array}$ & $\begin{array}{c}\text { Paper-and-pencil } \\
\text { self-administered }\end{array}$ & $\begin{array}{c}\text { Audio-CASI } \\
\text { self-administered }\end{array}$ \\
\hline Nyeri & 5 & $34 *$ & 5 \\
Sample size & 1,544 & 1,509 & 1,311 \\
Kisumu & $2^{*}$ & 41 & 37 \\
Sample size & 710 & 685 & 777 \\
\hline
\end{tabular}

* statistically significantly different from audio-CASI self-administered, $\mathrm{p}<0.05$ 
missing or nonresponse cases in the adolescent data by interview method. It should be noted, however, that the results for the two districts are not strictly comparable. The interview in Nyeri had a smaller number of questions and ended approximately halfway through if respondents reported that they had never had sex. In Kisumu, the survey was longer and respondents were asked additional questions about sexual behavior, pregnancies, births, and abortions regardless of their answer to the question about ever having sex.

The patterns that emerge from Table 4 for the paper-and-pencil interviewer-administered and paper-and-pencil self-administered surveys are what one would expect, almost universal completion rates for the former surveys and much higher levels of missing data for the latter. For the paper-and-pencil self-administered surveys, 34 percent of respondents in Nyeri and 41 percent in Kisumu had at least one missing value, with approximately one in ten surveys in both districts having four or more missing values (results not shown). Audio-CASI obtains similarly low levels of missing data as the interviewer-administered surveys in Nyeri, most likely a result of the fact that 60 percent of the sample reported never having had sex, and hence only completed half the survey. In Kisumu, the percentage of cases with missing and nonresponse data in audioCASI is much closer to that for the paper-and-pencil self-administered surveys, suggesting little gain from computerization. ${ }^{17}$ However, 53 percent of those who reported keypad problems had at least one missing value, compared with 35 percent of those not reporting such problems (results not shown), suggesting that a portion of the audioCASI missing values were not by choice of the respondent.

Although universal completion rates in the interviewer-administered mode are seen as desirable for data analysis, they are likely a consequence of respondents' being under social pressure to respond to the interviewer. Evidence from the audio-CASI results in Kisumu suggests that respondents, when completely free not to answer, might decide to skip questions with which they are uncomfortable. Having the ability to avoid certain questions is a premise underlying most protocols regarding human subjects and related consent forms and is arguably more ethically appropriate. Further, as we suggest elsewhere (Mensch, Hewett, and Erulkar 2003), obtaining an answer in the face-to-face interview does not ensure that it is truthful or correct. 


\section{Local context and data collection}

In addition to the technical challenges of carrying out a field-based audio-CASI survey, one should be mindful of the impact of computerized interviewing on the data collection process, particularly when the survey includes questions of a sensitive or personal nature. Reaction to the computerized interview can influence the acceptability of the survey and the willingness of parents and respondents to participate in the study. ${ }^{18}$ If computers are unknown or unfamiliar to the population among which they are being used, they may prove to be a cause of concern about the project activities. This is particularly the case in household-levels surveys where unknown visitors carrying notebook computers maybe viewed with suspicion.

Culling information from interviewer and supervisor reports reveals that, in Nyeri, the presence of computers heightened the animosity and opposition of the community and parents to project activities. In Kisumu, where the survey was received with greater tolerance, the computers did not seem to provoke much undue attention or concern. Partial support for this view comes from exit interviews, which reveal that in Nyeri 25 percent of the adolescent surveys using audio-CASI were conducted with someone besides the respondent and interview staff present during the interview. In Kisumu, interviews with others present occurred in only 3 percent of the audio-CASI surveys; this result was similar to that for paper-and-pencil interviewer-administered and self-administered surveys in both district.

In Nyeri, respondents, parents, and community leaders were particularly apprehensive about the computers, and rumors emerged. Word spread that the survey was the work of devil worshipers and that interviewers were collecting the names of adolescents who would later be abducted. Many respondents believed that the computers collected information for the government. Antagonism also arose because respondents were angry that expensive computers were brought into their resource-starved community, which, owing to drought and famine, was barely capable of producing enough food. In one community, in fact, an interviewer was physically assaulted and a van carrying interviewers was pelted with stones. Until recently, Nyeri district was the center of political opposition in a country in which opposing viewpoints were not well tolerated. ${ }^{19}$ While the province was relatively well-off during President Kenyatta's rule, increasing politi- 
cal divisions and uncertainty at the national level have resulted in a marked deterioration of Nyeri's economy and infrastructure in recent years. According to our field supervisors, many residents of Nyeri are distrustful of outsiders, and community and political leaders within Nyeri are often thought to reinforce these attitudes as a means of consolidating and maintaining loyalties. Furthermore, Nyeri is experiencing a rise in the influence of evangelical Christian groups that tend to suppress discussion of issues such as family planning and sexual behavior, especially among adolescents.

Evidence of the effect of local conditions on the fieldwork in Nyeri can be seen in Table 5, which shows the distribution of assignment of respondents to each of the three interview methods and the response rates for both Nyeri and Kisumu. In Nyeri, the lower proportion assigned to the audio-CASI interview method, coupled with lower response rates, is indicative of the problems that arose during fieldwork in this district. ${ }^{20}$

Table 5 Sample assignment to interview mode and response rates

\begin{tabular}{|c|c|c|c|c|}
\hline & $\begin{array}{l}\text { Paper-and-pencil } \\
\text { interviewer- } \\
\text { administered }\end{array}$ & $\begin{array}{c}\text { Paper-and-pencil } \\
\text { self- } \\
\text { administered }\end{array}$ & $\begin{array}{l}\text { Audio-CASI } \\
\text { self- } \\
\text { administered }\end{array}$ & Total \\
\hline \multicolumn{5}{|l|}{ Nyeri district } \\
\hline \multicolumn{5}{|l|}{ Boys } \\
\hline Target sample size & $700(33 \%)$ & $700(33 \%)$ & $700(33 \%)$ & 2,100 \\
\hline Assigned surveys & $954(35 \%)$ & $925(34 \%)$ & $854(31 \%)$ & 2,733 \\
\hline Completed surveys & $829(37 \%)$ & $750(33 \%)$ & $694(31 \%)$ & 2,273 \\
\hline \multicolumn{5}{|l|}{ Girls } \\
\hline Target sample size & $700(33 \%)$ & $700(33 \%)$ & $700(33 \%)$ & 2,100 \\
\hline Assigned surveys & $847(35 \%)$ & $869(35 \%)$ & $740(30 \%)$ & 2,456 \\
\hline Completed surveys & $732(35 \%)$ & $762(36 \%)$ & $599(29 \%)$ & 2,093 \\
\hline Response rate & $87 \%$ & $84 \%$ & $81 \%$ & $84 \%$ \\
\hline \multicolumn{5}{|l|}{ Kisumu district } \\
\hline \multicolumn{5}{|l|}{ Boys } \\
\hline Target sample size & $350(33 \%)$ & $350(33 \%)$ & $350(33 \%)$ & 1,500 \\
\hline Assigned surveys & $434(34 \%)$ & $399(31 \%)$ & $448(35 \%)$ & 1,281 \\
\hline Completed surveys & $361(32 \%)$ & $360(31 \%)$ & $417(37 \%)$ & 1,138 \\
\hline \multicolumn{5}{|l|}{ Girls } \\
\hline Target sample size & $350(33 \%)$ & $350(33 \%)$ & $350(33 \%)$ & 1,500 \\
\hline Assigned surveys & $380(32 \%)$ & $384(33 \%)$ & $419(35 \%)$ & 1,183 \\
\hline Completed surveys & $349(34 \%)$ & $325(31 \%)$ & $360(35 \%)$ & 1,034 \\
\hline Response rate & $87 \%$ & $87 \%$ & $89 \%$ & $88 \%$ \\
\hline
\end{tabular}


It is difficult to identify the reason for the lower assignment to audio-CASI, particularly for girls. Anecdotal evidence suggests that the interviewers, under pressure to complete the surveys and facing increasing antagonism from a suspicious population, were purposely not allocating interviews to the audio-CASI method; that is, on occasion, they deliberately avoided listing households with adolescents when audio-CASI was the specified interview mode on the household listing form. ${ }^{21}$ Another explanation, suggested by the fieldwork supervisors, is that staff who were assigned face-to-face or self-administered interviews over-allocated respondents to their own interview mode in the hope that, by conducting more interviews, they would be looked on favorably for possible future employment.

The response rates provide further evidence for differences in how the data collection teams were received in the two communities. The overall response rate for the audio-CASI method was lower in Nyeri, at 81 percent of assigned surveys, while the response rate for audio-CASI in Kisumu was 89 percent. Also, in Kisumu, the assignment and response rates were more evenly distributed, despite the smaller sample sizes. This is partially due to the change in the assignment method that prevented the interviewers from knowing the assigned method of interview for a household in advance. In addition, community members in Kisumu had no obvious objections to the project and interviewing staff. The interviewers indicated that for this district consent was difficult to obtain from only 3 percent of the parents and 2 percent of the adolescents. ${ }^{22}$

The difficulties in completing the daily activities in Nyeri extended the time required to complete the data collection. The accumulation of completed adolescent interviews by days of interviewing for each of the districts is shown in Figure 2. Difficulty in reaching our target number of surveys for audio-CASI is indicated by the widening gap over the course of fieldwork in Nyeri between audio-CASI and the other two methods of interviewing. Again, partly because of the lower assignment and partly because of the higher levels of nonresponse, the collection of audio-CASI interviews increasingly slowed data collection in Nyeri, particularly among girls. ${ }^{23}$ Fieldwork was stopped before the target number of surveys for audio-CASI was reached (694 male and 599 female surveys were completed) because of increasing costs, interviewer fatigue, and preliminary results that indicated larger differentials in reporting across methods than expected. 
Figure 2 Accumulation of interviews by method and district

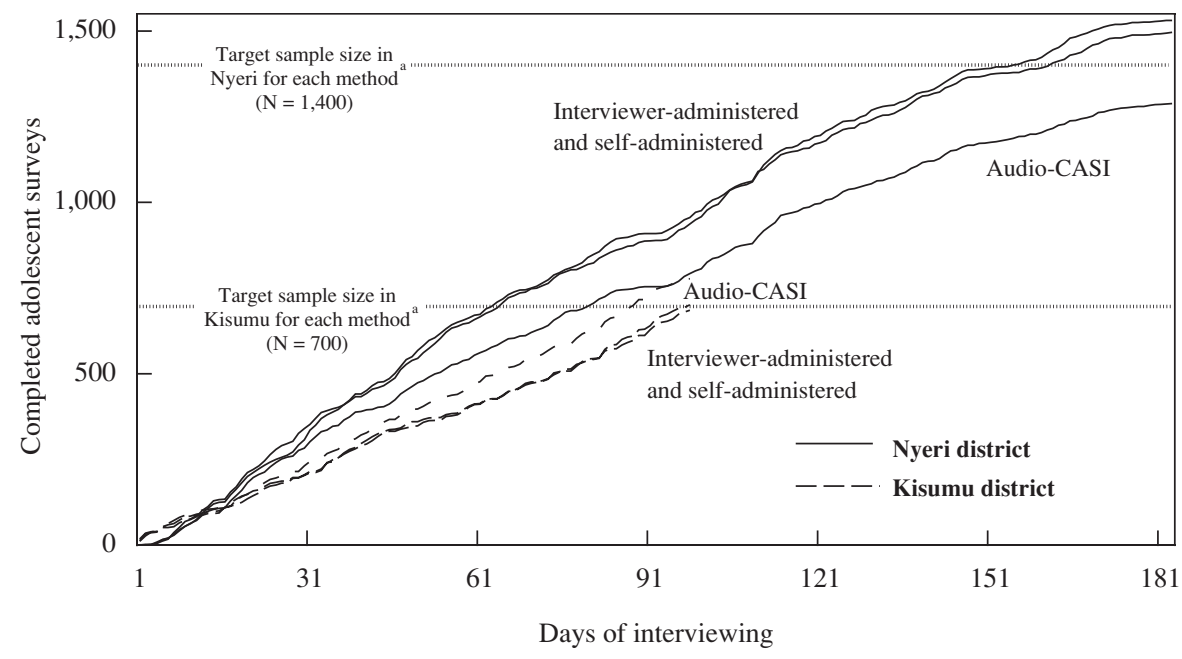

a Includes both boys and girls.

In Kisumu these patterns of assignment and collection are reversed and are primarily a function of the slightly higher rates of random assignment to the audio-CASI method and higher response rates. With larger sample sizes, the gap in the number of completed surveys for audio-CASI and the other methods of interviewing would likely close. It should be noted, however, that despite the difficulties of working in Nyeri the rates of collection were higher than in Kisumu, as represented by the steeper slope of the lines in Figure 2 for all methods in Nyeri. Although the number of interviewers and the structure of the interviewer teams were the same across districts, these differences may be attributable to the fact that in Nyeri the teams traveled in three vans, whereas in Kisumu only two vans were hired for fieldwork. The smaller number of vans slows down fieldwork slightly as teams typically had to wait until all interviewers finished their activities in an enumeration area before proceeding to the next sampled location.

Although these data are informative, our purpose is not to exaggerate the difficulties of fieldwork in Nyeri. While negative reaction to the survey did arise in some communities, it did not affect the majority of interviews. Our experiences do reveal, however, that the reaction to the survey in a subset of communities can have an impact 
on the actions of the interview staff, the quality of data collected, and the costs of the project. Admittedly, it is difficult to determine whether such events and conditions affected the adolescents' responses, particularly by interview mode. Given that computers are a poorly understood technology, it is reasonable to assume that the suspicion and antagonism of community members and respondents' parents in Nyeri may have had more of an impact on the audio-CASI interview than on other modes of administration.

\section{RESPONDENT EVALUATIONS}

Computerized self-interviewing is believed to provide a more confidential method of collecting survey data than more traditional methods. It relies on the respondents' perception of the interview as more private and, as a result, on their feeling more comfortable answering sensitive questions. The pertinent question is whether respondents actually believe that the computerized interview is more confidential and anonymous, particularly in cases where computers are an unfamiliar technology.

To evaluate this issue, respondents were asked in the exit interview whether they at any time felt embarrassed or uncomfortable. In Kisumu, two additional questions were added asking respondents whether they felt the interview was confidential and private. The results from these questions addressed to adolescent girls are shown by interview mode in Figure 3a for Nyeri and Figure 3b for Kisumu. This analysis is focused on girls since premarital sexual activity, the subject of the survey, is more stigmatized for girls, hence they are more likely than boys to alter their responses to conform to social norms. For this reason, they are also more likely to be sensitive to the mode of interview.

The data illustrated in Figure 3 do not provide support for the idea that respondents perceive the computerized self-interview much differently from the way they perceive the interviewer-administered or self-administered surveys. Although some differences are found in the expected direction in Kisumu, they are not strong or consistent enough to suggest that audio-CASI would provide significantly different reporting of sensitive behaviors than the other modes of survey administration. However, given the

wide differences in reporting of sensitive behaviors by interview mode that we observed (see Mensch, Hewett, and Erulkar 2003), it is likely that a courtesy bias exists in report- 
Figure 3a Female respondents' evaluation of the interview by interview method: Nyeri district

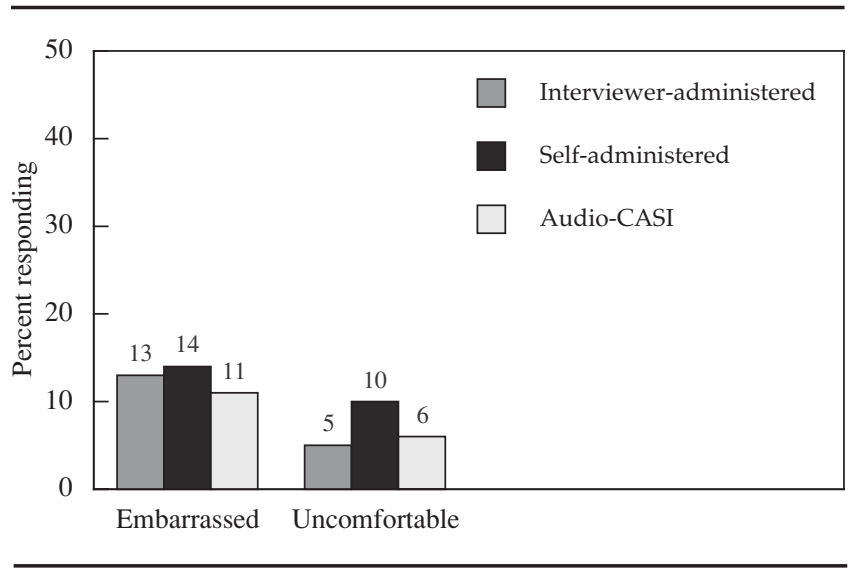

Figure 3b Female respondents' evaluation of the interview by interview method: Kisumu district

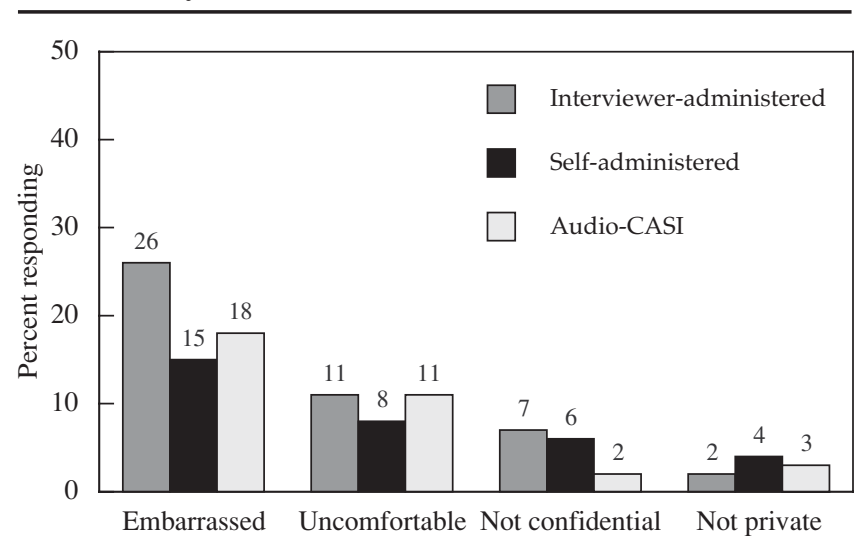

ing for these questions, since all respondents regardless of interview mode had a face-toface exit interview. In fact, field supervisors report that adolescents in Kenya are unlikely to provide negative feedback during an interview, suggesting that differences in perceived levels of privacy and confidentiality are greater than those observed in Figure 3. 


\section{DISCUSSION AND FURTHER RESEARCH}

We set out to review the outcome of a survey of more than 6,000 adolescents aged 15-21 years in rural Kenya and to evaluate the feasibility of an audio-CASI self-interview, relative to more traditional interviewing techniques, specifically paper-and-pencil self-administered and paper-and-pencil interviewer-administered surveys. The study was based on a quasi-experimental design in which adolescents were assigned to one of the three interview methods and asked questions regarding their background, as well as sensitive questions about such matters as sexual behavior and alcohol and drug use.

The audio-CASI technology performed quite well during approximately ten months of interviewing, despite the rigorous conditions of working in a largely rural, sub-Saharan African setting. Few problems arose with the audio-CASI software or computer hardware; the source of most problems derived from the external keypads and, to a lesser extent, the computer batteries. The adolescents in the study easily learned to use the headphones and keypad to answer the survey questions. Further, respondents in the audio-CASI mode were no more likely than other respondents to stop and ask for assistance during the interview. However, the substantial number of invalid entries made by respondents in the audio-CASI mode suggests that respondents did not completely master the use of the keypad during the interview.

The project was purposely set in a rural area to provide a rigorous test of the technical difficulties of fielding household-based computerized interviewing. The surveys were conducted among a population largely unfamiliar with computer technology. Given the limited number of problems experienced and the positive response from respondents, our experience indicates that computerized interviewing is a feasible method of collecting survey data in developing countries.

Despite the relative success of the audio-CASI component, some technical challenges remain to make this mode of interviewing more effective. A first step is to simplify or eliminate the external mini-keypad, perhaps using touch-screen technologies, which have been found to be an effective alternative (Lara et al. 2001). Handheld devices may be most suitable for these purposes since they do not require a separate keyboard and are based on a touch-screen approach to data input. However, touch-screen data 
entry procedures would have to be customized and tested for use among populations with low levels of literacy. Additionally, in the case of computer or battery failure, programming that returned to the point at which the interview terminated rather than reverting to the beginning would reduce interview times and streamline the survey process.

The overall success of computerized interviewing was also found to be dependent on the local context in which interviewing took place. In Kisumu, where community members were more favorably disposed to the survey, computerized interviewing was no more difficult to implement than other modes. The experience in Nyeri, on the other hand, suggests that where segments of the community have doubts about project activities, the use of computers can exacerbate the suspicions of parents and adolescents. This effect seemed to influence the data collection process, although its effect on data quality is harder to assess.

Understanding how computerized interviewing is perceived in developing countries is an important area of future research, particularly with regard to perceptions of privacy and confidentiality. The results from our exit interviews are not particularly illuminating in this respect. Although respondents reported that they were slightly less embarrassed in the audio-CASI interview and that the computerized interview was more confidential, they did not report the audio-CASI interview as being more comfortable or private. In-depth interviews and focus groups would likely provide greater insight into the nature of conducting the surveys with computers in developing countries, thereby shedding light as well on the reliability and validity of the data collected.

\section{NOTES}

This work could not have been completed without the diligent and meticulous work of the project supervisors, Kimundo Maina and Lucy Ng'ang'a in Nyeri and Francis Ayuka in Kisumu. In addition, special thanks is given to the interviewers and team supervisors, whose patience and fortitude were especially pronounced during a long and sometimes trying data collection process. We also acknowledge the invaluable technical advice and assistance provided by Stanley Mierzwa at the Population Council, New York. 
1 See Couper and Nicholls (1998) and Turner et al. (1998b) for overviews of the development of computerized interviewing and computerized interviewing in surveys with sensitive questions.

2 The age range was selected because reported levels of sexual activity are low in Kenya among adolescents under age 15 while marriage is common after age 21.

3 The results of Kenya's 1999 national census were not available at the time of the Nyeri survey. Kenya has seven administrative provinces. Within provinces, there are districts (e.g., Nyeri and Kisumu) that can be further subdivided geographically by location and sublocation. Sublocations are the lowest administrative unit in Kenya, roughly comparable to a "village." The size of sublocations varies from a few hundred households to 10,000 or more depending on urban, rural, and geographic settlement patterns. Selection of sublocations within the two districts was based on probabilities proportional to size. In Kisumu, sublocations were first stratified by urban and rural areas.

4 Only one adolescent per household was assigned to the study. If there was more than one adolescent in the age range, one was selected randomly, on the basis of a "Kish" grid.

5 While several studies in the United States have found that both men and women are more likely to disclose information about sexual activity to female interviewers, Catania (1997) presents evidence that same-sex interviewers increased reporting of sensitive behavior.

6 Each battery had an average life of two to three hours. Three batteries were made available on the premise that a maximum of three interviews per day would be conducted, one on each battery. In the course of fieldwork, the number of interviews rarely exceeded two.

7 The programming of the audio-CASI software was done by the principal investigators and is not included in this cost calculation. 
8 By far the most exacting technological challenge was that the audio files used approximately one gigabyte of memory. With newer audio-compression technologies, the required storage capacity has dropped.

9 All instructions, questions, and related response categories were individual audio files. They were recorded separately, rather than as part of a continuous audio stream.

10 To test whether the playback versus non-playback of responses produced a difference in reporting, a small sample of 300 adolescent girls was interviewed after the original fieldwork in Nyeri was completed. With half assigned to playback and half to non-playback, no differences were found between the two. The playback of responses was removed for Kisumu to reduce overall interview times and to eliminate concerns reported by some adolescents in Nyeri that playback indicated that someone was listening and responding to their answers.

11 The audio-CASI software was not programmed to return to the point at which the interview was disrupted.

12 The pretest took place a week prior to fieldwork in Nyeri and provided practice for the recently trained interviewers. Adolescents were given face-to-face interviews and were subsequently interviewed using the computer. A separate group of adolescents was interviewed using the self-administered questionnaires.

13 The most often cited reason for seeking assistance for all methods was clarification of the survey questions. Audio-CASI respondents could also ask for assistance in using the keypads and/or headphones, or to reveal computer malfunctions. The audio-CASI respondents were specifically told that they could stop and ask for assistance at any time during the interview. The computer program was designed to allow for such breaks in interviewing.

14 An invalid entry is one in which the entered response is outside the range of acceptable responses for that question-for instance, entering the number 3 when either a 1 (yes) or 2 (no) was appropriate. 
15 The counter used for Table 3 was programmed to count only the total number of repeated questions; it did not store information on which questions were repeated. The questions with counters, using slightly different wording for boys and girls, included: whether they have ever attended school, respondent's living arrangement, whether they suspect they have HIV/AIDS, whether they have ever smoked bhang/marijuana, whether they have gone to the disco without their parents' permission, whether they have ever had sex, total number of lifetime sexual partners, whether they or one of their partners has had an induced abortion, whether they have ever touched someone or have been touched in an unwanted way, and whether they have ever physically forced someone or have been forced to have sex.

16 Respondents who had at least one invalid entry were also twice as likely to ask the interviewer for assistance during the interview, although only 20 percent of audio-CASI respondents did so.

17 Missing responses were also evaluated by respondent's education and sex and by the sensitivity of the questions. No statistically significant differential effects were found by sex or education. Although there was a greater absolute number of missing responses for sensitive relative to nonsensitive questions, the percent missing was proportional to the number of sensitive questions in the survey.

18 In Kenya, as in other settings in Africa, one first has to obtain permission from tribal or community leaders before entering an area for interviewing. Any uncertainty, animosity, or opposition to the goals and actions of the project from community leaders or members can permeate throughout the community.

19 This changed with the December 2002 elections in which the opposition party candidate defeated the ruling party's presidential candidate for the first time in Kenya's history as an independent country.

20 Although the percentage difference between uniform distribution and the observed assignment does not exceed 5 percentage points in Table 5, given the large samples, the deviation from a random assignment is significant below the 0.001 level. 
21 In Nyeri, assignment to method was made using randomly labeled household listing forms. The forms allowed the interviewers to know which interview method would be assigned for a adolescent survey prior to the household interview. In Kisumu, assignment was done after the household listing was complete, using a random number generator in Microsoft Access.

22 These questions were added to the Kisumu exit interview given to interviewers in response to the difficulties noted in obtaining consent in Nyeri.

23 The different rates of collection are also a consequence of the higher total time per interview for audio-CASI. In Nyeri audio-CASI interviews had median times per interview (approximately 35 minutes) that were more than twice those of the interviewer-administered surveys (approximately 15 minutes). The self-administered surveys were minimally faster (approximately 33 minutes) than the audio-CASI surveys. Owing to changes in audio-CASI programming that removed the playback of respondents' answers for verification, the ratio of median times between interviewer-administered and audio-CASI dropped to 1.5 in Kisumu.

\section{REFERENCES}

Aquilino, William S. 1994. "Interview mode effects in surveys of drug and alcohol use: A field experiment," Public Opinion Quarterly 58(2): 210-240.

Aquilino, William S. and Leonard A. Lo Scuito. 1990. "Effects of interviewer mode on self-reported drug use," Public Opinion Quarterly 54(3): 362-395.

Beebe, Timothy J., Patricia A. Harrison, James A. Mcrae, Ronald E. Anderson, and Jayne Fulkerson. 1998. "An evaluation of computer assisted self-interviews in a school setting," Public Opinion Quarterly 62(4): 623-632.

Boekeloo, B.O., L. Schiavo, D.L. Rabin, R.T. Conlon, C.S. Jordan, and D.J. Mundt. 1994. "Self-reports of HIV risk factors by patients at a sexually transmitted disease clinic: Audio vs. written questionnaires," American Journal of Public Health 8(5): 754-760. 
Bradburn, Norman, Seymour Sudman, Ed Blair, and Carol Stocking. 1978. "Question threat and response bias," Public Opinion Quarterly 42(2): 221-234.

Bradburn, Norman, Seymour Sudman, and associates. 1979. Improving Interview Method and Questionnaire Design: Response Effects to Threatening Questions in Survey Research. San Francisco: Jossey-Bass.

Catania, Joseph A. 1997. "A model for investigating respondent-interviewer relationships in sexual surveys," pp. 417-435 in John Bancroft (ed.), Researching Sexual Behavior: Methodological Issues. Bloomington: Indiana University Press.

Cohen, Jacob. 1992. “A power primer,” Psychological Bulletin 112(1): 155-159.

Copas, Andrew J., Anne M. Johnson, and Jane Wadsworth. 1997. "Assessing participation bias in a sexual behaviour survey: Implications for measuring HIV risk," AIDS 11: 783-790.

Couper, M.P. and William L. Nicholls II. 1998. "The history and development of computer assisted survey information collection methods," pp. 1-22 in Mick P. Couper et al. (eds.), Computer Assisted Survey Information Collection. New York: Wiley.

Des Jarlais, D. et al. 1999. “Audio-computer interviewing to measure risk behavior for HIV among injecting drug users: A quasi-randomized trial," Lancet 353: 16571661.

Fenton, Kevin A., Anne M. Johnson, Sally McManus, and Bob Erens. 2001. "Measuring sexual behavior: Methodological challenges in survey research," Sexually Transmitted Infections 77: 84-92.

Fu, Haishan, Jacqueline E. Darroch, Stanley Henshaw, and Elizabeth Kolb. 1998. "Measuring the extent of abortion underreporting in the 1995 National Survey of Family Growth," Family Planning Perspectives 30(3): 128-138.

Jobe, J.B., W.F. Pratt, R. Tourangeau, A. Baldwin, and K. Rasinski. 1997. "Effects of interview mode on sensitive questions in a fertility survey," pp. 311-329 in L. Lyberg (ed.), Survey Measurement and Process Quality. New York: Wiley.

Johnson, A.M. et al. 2001. "Effect of computer assisted self interviews on reporting of sexual HIV risk behaviors in a general population sample: A methodological experiment," AIDS 15: 111-115. 
Kyrsan, Maria. 1998. "Privacy and the expression of white racial attitudes: A comparison across three contexts," Public Opinion Quarterly 62(4): 506-544.

Lara, Diana, Charlotte Ellertson, Claudia Diaz, and Jennifer Strickler. 2001. "Measuring the prevalence of induced abortion in Mexico City: Comparison of four methodologies," paper presented at the 24th Population Conference of the International Union for the Scientific Study of Population, Salvador de Bahia.

Lloyd, Cynthia B., Carol E. Kaufman, and Paul C. Hewett. 2000. "The spread of primary schooling in sub-Saharan Africa: Implications for fertility change," Population and Development Review 26(3): 483-515.

Macalino, G., D. Celentano, S. Strathdee, C. Latkin, and D. Vlahov. 2002. "Risk behaviors by audio computer-assisted self-interviews among HIV-seropositive and HIVseronegative injection drug users," AIDS Education and Prevention 14(5): 367378.

Mensch, Barbara S., Paul C. Hewett, and Annabel S. Erulkar 2003. "The reporting of sensitive behavior among adolescents: A methodological experiment in Kenya," Demography (forthcoming).

_. 2001. "The reporting of sensitive behavior among adolescents: A methodological experiment in Kenya," Research Division Working Paper No. 151. New York: Population Council.

Mensch, Barbara S., Judith Bruce, and Margaret E. Greene. 1998. The Uncharted Passage: Girls' Adolescence in the Developing World. New York: Population Council.

Mensch, Barbara S. and Denise B. Kandel. 1988. "Underreporting of substance use in a national longitudinal youth cohort: Individual and interviewer effects," Public Opinion Quarterly 52(1): 100-124.

Metzger, D.S., B. Koblin, H. Navaline, C. Turner, F. Valenti, S. Holte, M. Gross, A. Sheon, H. Miller, P. Cooley, and G.R. Seage 3rd. 2000. "Randomized controlled trial of audio computer-assisted self-interviewing: Utility and acceptability in longitudinal studies. HIVNET Vaccine Preparedness Study Protocol Team," American Journal of Epidemiology 152(2): 99-106. 
Millstein, S.G. and C.E. Irwin. 1983. "Acceptability of computer-acquired sexual histories in adolescent girls," Journal of Pediatrics 103: 815-819.

Murphy, Kevin R. and Brett Myors. 1998. Statistical Power Analysis: A Simple and General Model for Traditional and Modern Hypothesis Tests. Mahwah, NJ: L. Erlbaum Associates.

O'Reilly, J., M. Hubbard, J. Lessler, P. Biemer, and C. Turner. 1994. "Audio and video computer assisted self-interviewing: Preliminary tests of new technology for data collection," Journal of Official Statistics 10: 197-214.

Rumakom, Patchara, Philip Guest, Waranuch Chinvarasopak, Watit Utmarat, and Jiraporn Sontanakanit. 1999. "Obtaining accurate responses to sensitive questions: A comparison of two data collection techniques." Unpublished manuscript. Population Council, Bangkok, Thailand.

Tourangeau, Roger and Tom W. Smith. 1996. "Asking sensitive questions: The impact of data collection mode, question format, and question context," Public Opinion Quarterly 60(2): 275-304.

_ 1998. "Collecting sensitive information with different modes of data collection,” pp. 431-453 in Mick P. Couper et al., Computer Assisted Survey Information Collection. New York: Wiley.

Turner, C.F., L. Ku, M. Rogers, L.D. Lindberg, J.H. Pleck, and F.L. Sonenstein. 1998a. "Adolescent sexual behavior, drug use and violence: Increased reporting with computer survey technology," Science 280: 867-873.

Turner, C.F. et al. 1998b. "Automated self-interviewing and the survey measurement of sensitive behaviors," pp. 455-473 in Mick P. Couper et al., Computer Assisted Survey Information Collection. New York: Wiley.

van de Wijgert, Janneke, Nancy Padian, Stephen Shiboski, and Charles Turner. 2000. "Is audio computer-assisted self-interviewing a feasible method of surveying in Zimbabwe?" International Journal of Epidemiology 29: 885-890. 
Voeten, Helene, E.I. Meester, O.B. Egesah, and J.D.F. Habbema. 2000. "Experiences with method triangulation in a study on sexual behavior of young adults 15-29 years in Nyanza province, Kenya," paper presented at the IUSSP Conference on Partnership Networks, Chiang Mai, Thailand.

Warner, Stanley. 1965. "Randomized response: A survey technique for eliminating evasive answer bias," Journal of the American Statistical Association 60(309): 6369.

Williams, M.L., R.C. Freeman, A.M. Brown, Z. Zhao, W.N. Elwood, C. Gordon, P. Young, R. Rusek, and C.A. Signes. 2000. "A comparison of the reliability of selfreported drug use and sexual behaviors using computer assisted versus face to face interviewing," AIDS Education and Prevention 12(3): 199-213. 


\title{
POLICY RESEARCH DIVISION WORKING PAPERS
}

\author{
Recent Back Issues
}

144 John Bongaarts, "Household size and composition in the developing world."

145 John B. Casterline, Zeba A. Sathar, and Minhaj ul Haque, "Obstacles to contraceptive use in Pakistan: A study in Punjab."

146 Zachary Zimmer, Albert I. Hermalin, and Hui-Sheng Lin, "Whose education counts? The impact of grown children's education on the physical functioning of their parents in Taiwan."

147 Philomena Nyarko, Brian Pence, and Cornelius Debpuur, "Immunization status and child survival in rural Ghana."

*148 John Bongaarts and Zachary Zimmer, "Living arrangements of older adults in the developing world: An analysis of DHS household surveys."

149 Markos Ezra, "Ecological degradation, rural poverty, and migration in Ethiopia: A contextual analysis."
150 Cynthia B. Lloyd, Sahar El Tawila, Wesley H. Clark, and Barbara S. Mensch, "Determinants of educational attainment among adolescents in Egypt: Does school quality make a difference?"

151 Barbara S. Mensch, Paul C. Hewett, and Annabel Erulkar, "The reporting of sensitive behavior among adolescents: A methodological experiment in Kenya."

152 John Bongaarts, "The end of the fertility transition in the developed world."

153 Mark R. Montgomery, GebreEgziabher Kiros, Dominic Agyeman, John B. Casterline, Peter Aglobitse, and Paul Hewett, "Social networks and contraceptive dynamics in southern Ghana."

*154 Paul C. Hewett and Mark R. Montgomery, "Poverty and public services in developing-country cities."

* No longer available 
155 Zachary Zimmer, Linda G. Martin, and Ming-Cheng Chang, "Changes in functional limitations and survival among the elderly in Taiwan: 1993, 1996, and 1999."

156 John Bongaarts and Griffith Feeney, "How long do we live?"

157 Zachary Zimmer and Sovan Kiry Kim, "Living arrangements and socio-demographic conditions of older adults in Cambodia."

158 Geoffrey McNicoll, "Demographic factors in East Asian regional integration."

159 Carol E. Kaufman, Shelley Clark, Ntsiki Manzini, and Julian May, "How community structures of time and opportunity shape adolescent sexual behavior in South Africa."

160 Julia Dayton and Martha Ainsworth, "The elderly and AIDS: Coping strategies and health consequences in rural Tanzania."

161 John Bongaarts, "The end of the fertility transition in the developing world."
162 Naomi Rutenberg, Carol E. Kaufman, Kate Macintyre, Lisanne Brown, and Ali Karim, "Pregnant or positive: Adolescent childbearing and HIV risk in South Africa."

163 Barbara S. Mensch, Wesley H. Clark, and Dang Nguyen Anh, "Premarital sex in Vietnam: Is the current concern with adolescent reproductive health warranted?"

164 Cynthia B. Lloyd, Cem Mete, and Zeba A. Sathar, "The effect of gender differences in primary school access, type, and quality on the decision to enroll in rural Pakistan."

165 Kelly Hallman, Agnes R. Quisumbing, Marie Ruel, and Bénédicte de la Brière, "Childcare, mothers' work, and earnings: Findings from the urban slums of Guatemala City."

166 Carol E. Kaufman and Stavros E. Stavrou, "Bus fare, please': The economics of sex and gifts among adolescents in urban South Africa."

167 Dominic K. Agyeman and John B. Casterline, "Social organization and reproductive behavior in southern Ghana." 
168 Paul C. Hewett, Annabel S. Erulkar, and Barbara S. Mensch, "The feasibility of computer-assisted survey interviewing in Africa: Experience from two rural districts in Kenya." 